\title{
Repeated radioembolization in advanced liver cancer
}

\author{
Max Masthoff ${ }^{\text {\#\# }}$, Philipp Schindler ${ }^{1 \#}$, Fabian Harders ${ }^{1}$, Walter Heindel ${ }^{1}$, Christian Wilms ${ }^{2}$, Hartmut H. Schmidt ${ }^{2}$, \\ Andreas Pascher ${ }^{3}$, Lars Stegger ${ }^{4}$, Kambiz Rahbar ${ }^{4}$, Moritz Wildgruber ${ }^{1,5}$, Michael Köhler ${ }^{1}$ \\ ${ }^{1}$ Institute of Clinical Radiology, ${ }^{2}$ Department of Gastroenterology and Hepatology, ${ }^{3}$ Department for General, Visceral and Transplantation Surgery, \\ ${ }^{4}$ Department of Nuclear Medicine, University Hospital Muenster, Muenster, Germany; ${ }^{5}$ Klinik und Poliklinik für Radiologie, Klinikum der \\ Universität München, Munich, Germany \\ Contributions: (I) Conception and design: M Masthoff, P Schindler, K Rahbar, M Wildgruber, M Köhler; (II) Administrative support: W Heindel, \\ HH Schmidt, A Pascher, L Stegger; (III) Provision of study materials or patients: F Harders, C Wilms, L Stegger, K Rahbar, M Wildgruber, M \\ Köhler; (IV) Collection and assembly of data: M Masthoff, P Schindler, F Harders, M Wildgruber; (V) Data analysis and interpretation: M Masthoff, \\ P Schindler, F Harders, M Wildgruber, M Köhler; (VI) Manuscript writing: All authors; (VII) Final approval of manuscript: All authors. \\ \#These authors contributed equally to this work. \\ Correspondence to: Max Masthoff, MD, MBA. Institute of Clinical Radiology, University Hospital of Muenster, Albert-Schweitzer-Campus 1, 48149 \\ Münster, Germany. Email: max.masthoff@ukmuenster.de.
}

\begin{abstract}
Background: To evaluate safety and clinical outcome of repeated transarterial ${ }^{90} \mathrm{Y}$ (yttrium) radioembolization (TARE) in primary and metastatic liver cancer.

Methods: Between 2009 and 2018, n=288 patients underwent TARE for treatment of malignant liver disease in a tertiary care hospital. This retrospective single center study analyzed the safety and outcome of patients $(n=11 / 288)$ undergoing repeated resin microsphere TARE. Included patients suffered from hepatocellular carcinoma $(n=3)$, colorectal cancer $(n=2)$, breast cancer $(n=2)$, intrahepatic cholangiocarcinoma $(\mathrm{n}=3)$, and neuroendocrine carcinoma $(\mathrm{n}=1)$. All patients had shown either partial response $(\mathrm{n}=9)$ or stable disease ( $n=2)$ after first TARE. Lab parameters, response assessed by the Response Evaluation Criteria in Solid Tumors (mRECIST/RECIST) at 3 months and overall survival was analyzed. Additionally, patients with repeated TARE were compared to a matched control group $(n=56)$ with single TARE therapy. Kaplan Meier analysis was performed to analyze survival.
\end{abstract}

Results: Patients after repeated TARE showed similar increase in lab parameters as compared to their first TARE. No case of radioembolization induced liver disease was observed. While $n=5 / 11$ patients showed a partial response and $n=4 / 11$ patients a stable disease after repeated TARE, only $n=2 / 11$ patients suffered from progressive disease. Median overall survival was $20.9 \pm 11.9$ months for the repeated TARE group while it was 5.9 16.2 months for the control group.

Conclusions: Repeated ${ }^{90} \mathrm{Y}$ TARE is safe and can be of benefit for patients yielding a comparable degree of local disease control compared to patients with singular TARE.

Keywords: Repeated radioembolization; ${ }^{90} \mathrm{Y}$ yttrium; liver cancer

Submitted Mar 18, 2020. Accepted for publication Apr 27, 2020.

doi: 10.21037/atm-20-2658

View this article at: http://dx.doi.org/10.21037/atm-20-2658

\section{Introduction}

Various local-ablative treatment options exist for primary and secondary liver cancer, such as radiofrequency ablation (RFA), microwave ablation (MWA) or transarterial chemoembolization (TACE) $(1,2)$. While most of these methods are used for earlier stages of disease, transarterial radioembolization (TARE) with ${ }^{90} \mathrm{Y}$-loaded glass or resin microspheres is a treatment option especially for advanced liver disease. Several studies analyze the potential of TARE in different entities or disease stages. While recent studies showed no benefit of survival of first-line TARE 
added to chemotherapy for colorectal cancer metastasis (3) or of TARE added to Sorafenib for HCC treatment (4), TARE showed beneficial in advanced HCC, intrahepatic cholangiocarcinoma or colorectal cancer metastasis of distinct origin (5-8). Within these studies, TARE proofed to be a safe method with high rates of local disease control. However, toxicity with consecutive adverse events have been reported, including gastrointestinal ulcers, cytopenia, post-embolization syndrome (fatigue, fever, pain, nausea), a decrease in liver function or radioembolization-induced liver disease (REILD; ascites, hepatic insufficiency, jaundice) (7-11). Within this context, experience in outcome as well as toxicity of repeated TARE is limited especially in patients with multiple other therapies before presented to TARE (12-14).

We therefore aimed to evaluate the safety and outcome of repeated ${ }^{90} \mathrm{Y}$ radioembolization for treatment of advanced liver cancer in a retrospective single-center cohort. We present the following article in accordance with the STROBE reporting checklist (available at http://dx.doi. org/10.21037/atm-20-2658).

\section{Methods}

\section{Study design}

The study was carried out as a retrospective single-center observational trial in a tertiary care academic medical center in Germany. The study was conducted in accordance with the Declaration of Helsinki (as revised in 2013). The study was approved by the local ethics committee of the Westfälische Wilhelms-University of Muenster, Germany (No.: 2018-638-f-S). Due to the retrospective character of this trial informed consent of patients was not obtained.

\section{Patient selection}

Patients with a repeated ${ }^{90} \mathrm{Y}$ radioembolization $(\mathrm{n}=11)$, identified from all patients with TARE $(n=288)$, in our center between 2009 to 2018 were assigned to the "repeated TARE" group. All patients undergoing TARE had approval of the interdisciplinary gastrointestinal tumor board. Diagnosis was based on the according European guidelines, respectively (15-19). Assignment to TARE (first as well as repeated TARE) was under premise of adequate hepatic function (Child-Pugh liver function grade A or B; ALT and AST $\leq 5 \times$ upper limit of normal (ULN); total bilirubin $\leq 1.5 \mathrm{ULN}$; albumin $\geq 29 \mathrm{~g} / \mathrm{L}$ ) as well as adequate hematologic, clotting and renal function tests. Moreover, hepatopulmonary shunt fraction had to be less than $20 \%$ and life expectancy was supposed to be more than 12 weeks.

In a second step patients identified from all other patients with a single TARE $(\mathrm{n}=277)$ by a propensity score matching considering sex, tumor entity, previous therapy, hepatic tumor burden and pre-therapeutic bilirubin were assigned to the "control group" $(\mathrm{n}=57)$.

\section{Procedure details}

After evaluation and preparation of radioembolization by using ${ }^{99 \mathrm{~m}}$ Tc-MAA following embolization of aberrant vasculature originating from the hepatic circulation, patients underwent planar whole body and SPECT/CT scanning of the thoracic and abdominal region (GE Discovery NM630 or Siemens Symbia T2) using low energy collimators for dose calculation, detection of extrahepatic tracer accumulation and assessment of hepato-pulmonary shunting. The maximum pulmonary shunt fraction accepted was $20 \%$. In case of positive TARE evaluation, ${ }^{90} \mathrm{Y}$ radioembolization using resin microspheres (SIRSpheres ${ }^{\circledR}$; Sirtex Medical, Sydney, Australia) was performed according to standard operating procedures. The ${ }^{90} \mathrm{Y}$ dose was calculated by the physicists and board-certified nuclear medicine physicians in the department of nuclear medicine. The body surface area (BSA) method was used for dose calculation [activity of SIR-Spheres in GBq= $(\mathrm{BSA}-0.2)+$ (volume of tumor/volume of whole liver)].

The angiographic therapeutic procedures were solely performed by interventional radiologists who were approved within the quality assurance program of the microsphere provider in cooperation with nuclear medicine specialists responsible for the microsphere administration. Either a ${ }^{90} \mathrm{Y}$ Bremsstrahl PET/CT or PET/MRI scan was performed following the procedures for documentation of the regional distribution of radioactivity within the liver.

Diagnostic imaging for follow-up after therapy was performed with biphasic dynamic contrast-enhanced CT or triphasic contrast-enhanced MR with hepato-cellular phase imaging.

\section{Data collection}

All patient and procedural data including laboratory parameters as well as follow-up/survival data were retrospectively acquired from the electronic patient's records as well as from the Picture Archiving and 
Communications System (PACS). Data collection and analysis was performed in 2019 and 2020. Tumor responses were based on comparative evaluation of pre- and posttreatment scans and evaluated by the Response Evaluation Criteria in Solid Tumors (RECIST), version 1.1, or in case of HCC by modified RECIST (mRECIST).

\section{Statistical analysis}

Data are shown as total number and percentage, mean and standard deviation or median and range or $95 \%$ confidence interval (CI), as appropriate. Kaplan-Meier analysis was performed to analyze survival, followed by log-rank test to compare the survival distributions of two groups. Casecontrol-matching was performed by propensity scorematching method with SPSS fuzzy extension. Propensity score-matching was performed via binary logistic regression to create a propensity score for each patient, entering the following variables: sex, tumor entity, previous therapy, hepatic tumor burden and pre-therapeutic bilirubin. Subsequently, a case-control match between the repeated TARE- and single TARE-group was obtained by use of the nearestneighborhood-matching using a caliper width of 0.2 without replacement (20). A P value $<0.05$ was considered statistically significant. Statistical analysis was performed using the SPSS Statistics version 26 (SPSS Inc., Chicago, IL, USA).

\section{Results}

\section{Patient characteristics}

11 patients with repeated TARE were included [median age, 60 y (50-78 y); $n=4$ male, $n=7$ female]. Patients suffered from various disease entities (HCC $n=3$, colorectal cancer $\mathrm{n}=2$, breast cancer $\mathrm{n}=2$, intrahepatic cholangiocarcinoma $\mathrm{n}=3$, neuroendocrine carcinoma $\mathrm{n}=1$ ). Limited extrahepatic tumor burden was present in $\mathrm{n}=7$ patients. Of 11 patients with repeated TARE, $n=9$ patients had previous therapies before the first TARE. Here, all 9 patients had previous chemotherapy, 3 patients had surgery and 1 patient each had TACE, radiotherapy or transplantation before second TARE. 2 patients had no other therapy before second TARE. Patients had shown either partial response $(n=9)$ or stable disease $(\mathrm{n}=2)$ after first TARE. Hepatic tumor burden before second TARE was $<25 \%$ in 2 patients, $25-50 \%$ in 8 patients and $>50 \%$ in 1 patient. Patient characteristics of the repeated TARE group are summarized in Table 1.

A total of $n=57$ patients were identified for the matched control group [median age, 62 y $(37-83$ y); $\mathrm{n}=29$ male, $\mathrm{n}=27$ female]. As Table 1 reveals, there were no significant differences regarding sex, tumor entity, previous therapies, hepatic tumor burden or pre-therapeutic bilirubin between the "repeated TARE" and the "control" group. Patients of control group received either chemotherapy $(\mathrm{n}=11,19.6 \%)$, transplantation, radiotherapy, radiochemotherapy (all $\mathrm{n}=1$, $1.8 \%)$, TACE $(n=2,3.6 \%)$ or no further therapy $(n=33$, $58.9 \%)$ after first TARE.

\section{Procedural characteristics}

All radioembolization procedures were performed on an inpatient basis. Repeated application of resin SIR spheres was performed either in a monolobar ( $\mathrm{n}=7$ right lobe, $\mathrm{n}=1$ left lobe) or bilobar $(\mathrm{n}=3)$ catheter position. In all cases, the application of SIR spheres was performed via a coaxial microcatheter in a selective or super-selective manner. Median applied dose for the second TARE was $1.5 \mathrm{GBq}$ while it was $1.4 \mathrm{GBq}$ for the first TARE. All procedural characteristics of repeated TARE group are summarized in Table 1.

\section{Safety of repeated TARE}

The increase in bilirubin ( $\Delta$ post TARE minus pre TARE bilirubin) was significantly higher within second TARE compared to after first TARE (Table 2), but absolute values of bilirubin after second TARE $(0.9 \pm 0.4)$ were still within the standard range $(<1.2 \mathrm{mg} / \mathrm{dL})$. Increase in ALT, AST and $\gamma$ GT ( $\Delta$ post TARE minus pre TARE) was not significantly different for second TARE compared to first TARE. There was no significant difference in bilirubin, $\gamma$ GT, ALT or AST values after second TARE compared to values after first TARE. 3 patients had new ascites after second TARE. No case of radioembolization induced liver disease was observed.

\section{Tumor response and survival}

In the 3 -month follow-up $n=5 / 11$ patients $(45.5 \%)$ had a partial response and $n=4 / 11$ patients $(36.4 \%)$ had a stable disease after second TARE. Only $n=2$ patients $(18.2 \%)$ had a progressive disease. Hereby, hepatic tumor burden was reduced from $25-50 \%$ to $<25 \%$ in 2 patients. Tumor response rates for repeated TARE group are summarized in Table 3.

Median survival with 20.9 months was significantly longer in case of repeated TARE compared to control group without second TARE (5.9 months, $\mathrm{P}=0.005$, 
Table 1 Baseline characteristics of patients with repeated TARE ( $\mathrm{n}=11)$ and retrospectively matched control group ( $\mathrm{n}=57)$

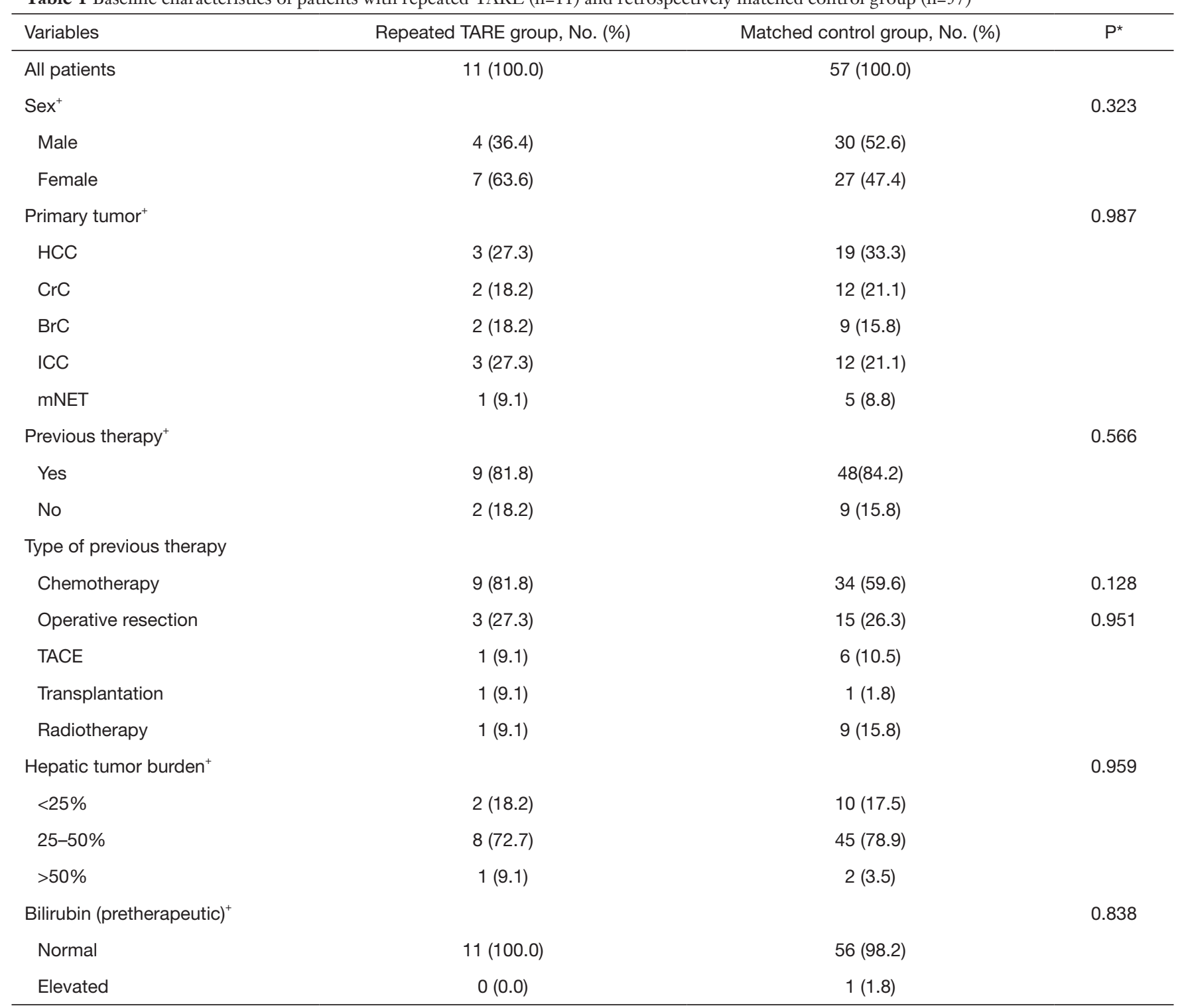

*, P value. No., number; ${ }^{+}$, matching variable; HCC, hepatocellular carcinoma; CrC, colorectal cancer; BrC, breast cancer; ICC, intrahepatic cholangiocarcinoma; mNET, metastatic neuroendocrine tumor; TACE, transarterial chemoembolization; TARE, transarterial radioembolization.

Table 2 Laboratory parameters for repeated TARE group before and after first or second TARE, respectively

\begin{tabular}{|c|c|c|c|c|c|c|c|c|c|c|}
\hline Parameters & Unit & Pre, 1. TARE & After, 1. TARE & $\triangle$, 1. TARE & Pre, 2. TARE & After, 2. TARE & $\triangle$, 2. TARE & $\Delta$, repeated TARE & $\mathrm{P}^{\#}$ & $\mathrm{P}^{+}$ \\
\hline ALT & $U / L$ & 27 & 34 & 7 & 41 & 37 & -4 & 10 & 0.706 & 0.026 \\
\hline AST & $U / L$ & 32 & 55 & 23 & 51 & 63 & 12 & 31 & 0.717 & 0.013 \\
\hline yGT & $U / L$ & 84 & 165 & 81 & 191 & 165 & -26 & 91 & 0.305 & 0.031 \\
\hline
\end{tabular}

$\Delta$ : delta (after 1. or 2. TARE minus 1. or 2. TARE, respectively or in case of $\triangle$ repeated TARE as after 2. TARE minus pre 1. TARE). P values are shown as $\mathrm{P}^{\#}$ for $\triangle 1$. TARE vs. $\triangle 2$. TARE and $\mathrm{P}^{+}$for pre 1. TARE vs. after 2. TARE. TARE, transarterial radioembolization; ALT, alanine transaminase; AST, aspartate aminotransferase; yGT, y-glutamyl transpeptidase. 
Table 3 Characteristics of repeated TARE group for first or second TARE, respectively

\begin{tabular}{|c|c|c|c|}
\hline Variables & 1. TARE, No. (\%) & 2. TARE, No. (\%) & $\mathrm{P}^{*}$ \\
\hline $\begin{array}{l}\text { Hepatic tumor bur- } \\
\text { den }\end{array}$ & & & 0.157 \\
\hline$<25 \%$ & $2(18.2)$ & $4(36.4)$ & \\
\hline $25-50 \%$ & $8(72.7)$ & $6(54.5)$ & \\
\hline$>50 \%$ & $1(9.1)$ & $1(9.1)$ & \\
\hline $\begin{array}{l}\text { Hepatopulmonary } \\
\text { shunt (\%) }\end{array}$ & $5.6(3.0-10.7)$ & $6.4(3.0-12.5)$ & 0.285 \\
\hline Applied dose (GBq) & 1.366 & 1.500 & 0.966 \\
\hline \multicolumn{4}{|l|}{ Lobe treated } \\
\hline Right & $8(72.7)$ & $7(63.6)$ & 0.888 \\
\hline Left & $0(0.0)$ & $1(9.1)$ & \\
\hline Both & $3(27.3)$ & $3(27.3)$ & \\
\hline Post-TARE ascites & & & 0.083 \\
\hline Yes & $0(0.0)$ & $3(27.3)$ & \\
\hline No & $11(100.00)$ & $8(72.7)$ & \\
\hline REILD & & & 1.000 \\
\hline Yes & $0(0.0)$ & $0(0.0)$ & \\
\hline No & $100(100.0)$ & $100(100.0)$ & \\
\hline \multicolumn{3}{|c|}{ Response (RECIST or mRECIST for HCC) } & 0.058 \\
\hline CR & $0(0.0)$ & $0(0.0)$ & \\
\hline PR & 9 (81.8) & 5 (45.5) & \\
\hline SD & 2 (18.2) & $4(36.4)$ & \\
\hline PD & $0(0.0)$ & 2 (18.2) & \\
\hline
\end{tabular}

*, $\mathrm{P}$ value. No., number; TARE, transarterial radioembolization; REILD, radioembolization induced liver disease; CR, complete response; PR, partial response; SD, stable disease; PD, progressive disease.

Figure $1 A$ ), despite similar disease extent und tumor burden. Median survival was also significantly longer in case of repeated TARE (20.9 months) compared to the subcontrol group with chemotherapy only after first TARE (7.4 months, Figure $1 B$ ) as well as compared to the subcontrol group without any therapy after first TARE (5.9 months, $\mathrm{P}=0.011$ ).

\section{Discussion}

${ }^{90} \mathrm{Y}$ TARE is a promising treatment option in primary and
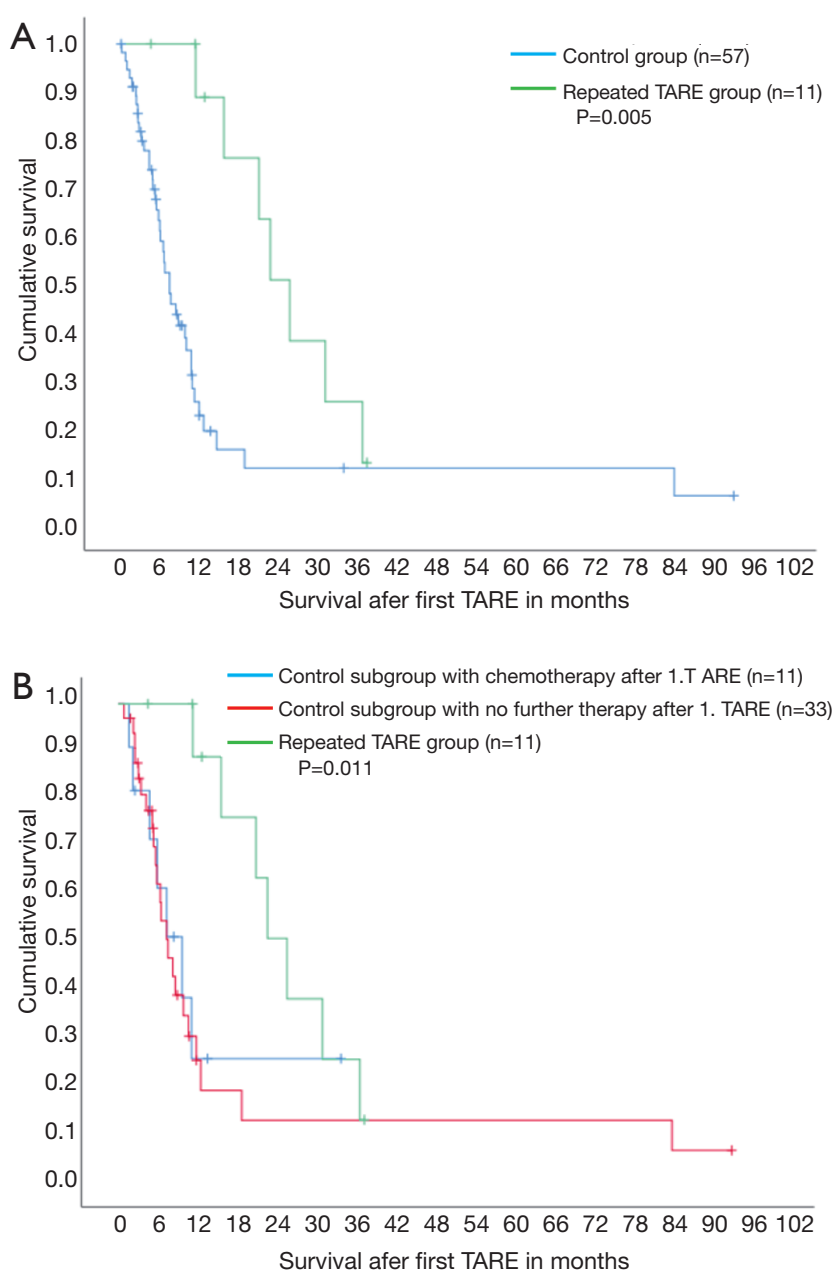

Figure 1 Kaplan-Meier analysis of survival after repeated ${ }^{90} \mathrm{Y}$ TARE. (A) A significantly higher cumulative survival of patients with repeated TARE ( $\mathrm{n}=11$ ) was observed as compared to matched control group without repeated TARE ( $\mathrm{n}=57 ; \mathrm{P}=0.005)$. (B) A significantly higher cumulative survival of patients with repeated TARE ( $n=11$ ) was observed as compared to control subgroups with chemotherapy or no further therapy after first TARE ( $\mathrm{n}=11$ or $\mathrm{n}=33$ respectively, $\mathrm{P}=0.011) .{ }^{90} \mathrm{Y}$, yttrium-90; TARE, transarterial radioembolization.

secondary liver cancer (21). Although multicenter studies showed no benefit in overall survival for first-line TARE combined with chemotherapy or sorafenib respectively $(3,4)$, there are reports of effective and safe TARE in the latter therapy options after first-line strategies have failed or are not feasible due to advanced tumor progression $(7,9,10,22)$. Along with the advancements in chemotherapy protocols and immunotherapies TARE will probably be integrated in 
multimodal treatment setting $(8,23)$. Within these concepts it is important to be aware of adverse events reducing patient safety. Although a variety of side effects can occur after TARE treatment $(7,9,10,24)$, there is limited evidence on safety of repeated TARE (12-14). This study shows that repetition of TARE is accompanied by a similar alteration of laboratory values as compared to first TARE and no severe liver decompensations in terms of REILD were observed in our patient cohort. However, 3 patients (27.3\%) developed ascites after second TARE. Since Lam et al. found in a study of $n=8$ patients an increased risk of REILD due to repeated TARE (14), patients should be carefully monitored after second TARE. However, the results of our study are in line with a previous study on repeated TARE in liver cancer, where a preserved liver function and a similar number of adverse events comparable to first TARE were observed (13). A second study in intrahepatic cholangiocarcinoma (ICC) similarly showed a favorable risk profile of repeated TARE with no case of REILD (12). In HCC, larger studies including some patients with sequential and repetitive TARE procedures found an acceptable risk of liver toxicity $(8,11)$. However, these studies do not report toxicity, therapy response or survival of patients receiving repeated TARE compared to patients with single TARE.

Regarding outcome of repeated TARE, we observed a good tumor control rate with a $45.5 \%$ partial response and $36.4 \%$ stable disease rate after 3 months. For repeated TARE in ICC a relevant part of complete response has been described (12), which we did not observe in our study. The tumor response rates after repeated TARE from our study are comparable to data from existing literature after first TARE (23). To the best of our knowledge, we provide the first study comparing overall survival after repeated TARE with a retrospectively matched control group which received only single TARE and various therapies afterwards. Here, repeated TARE showed a significantly longer overall survival compared to the control group in its entirety as well as compared to the control subgroup receiving systemic chemotherapy after first TARE. Our results could be influenced by the allocation to second TARE only in case of local tumor control or therapy response after first TARE with potentially including more advantageous (molecular) cancer characteristics. Our results might therefore not be veritable in case of a progressive disease after first TARE. However, the retrospective matching process used in this study considered with tumor entity, hepatic tumor burden and previous therapy (amongst others) factors, which showed to be predictors of overall survival after TARE (25).
Thus, repeated TARE should be considered as therapy option in advanced liver cancer.

This study is limited by its retrospective character and the heterogeneity of the analyzed patient cohort hampering generalizability, especially with regard to previous therapies and underlying disease entity, which is known to have a significant impact on safety especially with respect to liver function.

In conclusion, the present study shows that repeated ${ }^{90} \mathrm{Y}$ TARE can be considered as a safe treatment option with similar local tumor control compared to first TARE and improved overall survival compared to other treatment paths or solely palliative care in advanced liver cancer.

\section{Acknowledgments}

Funding: None.

\section{Footnote}

Reporting Checklist: The authors have completed the STROBE reporting checklist. Available at http://dx.doi. org/10.21037/atm-20-2658

Data Sharing Statement: Available at http://dx.doi. org/10.21037/atm-20-2658

Conflicts of Interest: All authors have completed the ICMJE uniform disclosure form (available at http:// dx.doi.org/10.21037/atm-20-2658). KR, MW, MK report receiving lectureship compensations and/or proctoring fees by SIRTeX Medical Europe, outside the submitted work. The other authors have no conflicts of interest to declare.

Ethical Statement: The authors are accountable for all aspects of the work in ensuring that questions related to the accuracy or integrity of any part of the work are appropriately investigated and resolved. The study was conducted in accordance with the Declaration of Helsinki (as revised in 2013). The study was approved by the local ethics committee of the Westfälische Wilhelms-University of Muenster, Germany (No.: 2018-638-f-S). Due to the retrospective character of this trial informed consent of patients was not obtained.

Open Access Statement: This is an Open Access article distributed in accordance with the Creative Commons Attribution-NonCommercial-NoDerivs 4.0 International 
License (CC BY-NC-ND 4.0), which permits the noncommercial replication and distribution of the article with the strict proviso that no changes or edits are made and the original work is properly cited (including links to both the formal publication through the relevant DOI and the license). See: https://creativecommons.org/licenses/by-nc-nd/4.0/.

\section{References}

1. Li D, Kang J, Golas BJ, et al. Minimally invasive local therapies for liver cancer. Cancer Biol Med 2014;11:217-36.

2. Crocetti L, Bargellini I, Cioni R. Loco-regional treatment of HCC: current status. Clin Radiol 2017;72:626-35.

3. Wasan HS, Gibbs P, Sharma NK, et al. First-line selective internal radiotherapy plus chemotherapy versus chemotherapy alone in patients with liver metastases from colorectal cancer (FOXFIRE, SIRFLOX, and FOXFIREGlobal): a combined analysis of three multicentre, randomised, phase 3 trials. Lancet Oncol 2017;18:1159-71.

4. Ricke J, Klumpen HJ, Amthauer H, et al. Impact of combined selective internal radiation therapy and sorafenib on survival in advanced hepatocellular carcinoma. J Hepatol 2019;71:1164-74.

5. Gibbs P, Heinemann V, Sharma NK, et al. Effect of Primary Tumor Side on Survival Outcomes in Untreated Patients With Metastatic Colorectal Cancer When Selective Internal Radiation Therapy Is Added to Chemotherapy: Combined Analysis of Two Randomized Controlled Studies. Clin Colorectal Cancer 2018;17:e617-29.

6. Hoffmann RT, Paprottka PM, Schon A, et al. Transarterial hepatic yttrium-90 radioembolization in patients with unresectable intrahepatic cholangiocarcinoma: factors associated with prolonged survival. Cardiovasc Intervent Radiol 2012;35:105-16.

7. Klompenhouwer EG, Dresen RC, Verslype C, et al. Safety and Efficacy of Transarterial Radioembolisation in Patients with Intermediate or Advanced Stage Hepatocellular Carcinoma Refractory to Chemoembolisation. Cardiovasc Intervent Radiol 2017;40:1882-90.

8. Salem R, Gabr A, Riaz A, et al. Institutional decision to adopt $\mathrm{Y} 90$ as primary treatment for hepatocellular carcinoma informed by a 1,000-patient 15-year experience. Hepatology 2018;68:1429-40.

9. Benson AB, 3rd, Geschwind JF, Mulcahy MF, et al. Radioembolisation for liver metastases: results from a prospective 151 patient multi-institutional phase II study. Eur J Cancer 2013;49:3122-30.
10. Bester L, Meteling B, Pocock N, et al. Radioembolisation with Yttrium-90 microspheres: an effective treatment modality for unresectable liver metastases. J Med Imaging Radiat Oncol 2013;57:72-80.

11. Gao R, Gabr A, Mouli S, et al. Toxicity and Survival of Hepatocellular Carcinoma Patients with Hepatitis B Infection Treated with Yttrium-90 Radioembolization: An Updated 15-Year Study. J Vasc Interv Radiol 2020;31:401-8.e1.

12. Filippi L, Di Costanzo GG, Tortora R, et al. Repeated Treatment with (90)Y-Microspheres in Intrahepatic Cholangiocarcinoma Relapsed After the First Radioembolization. Cancer Biother Radiopharm 2019;34:231-7.

13. Zarva A, Mohnike K, Damm R, et al. Safety of repeated radioembolizations in patients with advanced primary and secondary liver tumors and progressive disease after first selective internal radiotherapy. J Nucl Med 2014;55:360-6.

14. Lam MG, Louie JD, Iagaru AH, et al. Safety of repeated yttrium-90 radioembolization. Cardiovasc Intervent Radiol 2013;36:1320-8.

15. Galle PR, Forner A, Llovet JM, et al. EASL Clinical Practice Guidelines: Management of hepatocellular carcinoma. J Hepatol 2018;69:182-236.

16. Oberg K, Knigge U, Kwekkeboom D, et al. Neuroendocrine gastro-entero-pancreatic tumors: ESMO Clinical Practice Guidelines for diagnosis, treatment and follow-up. Ann Oncol 2012;23 Suppl 7:vii124-30.

17. Senkus E, Kyriakides S, Ohno S, et al. Primary breast cancer: ESMO Clinical Practice Guidelines for diagnosis, treatment and follow-up. Ann Oncol 2015;26 Suppl 5:v8-30.

18. Valle JW, Borbath I, Khan SA, et al. Biliary cancer: ESMO Clinical Practice Guidelines for diagnosis, treatment and follow-up. Ann Oncol 2016;27:v28-37.

19. Van Cutsem E, Cervantes A, Adam R, et al. ESMO consensus guidelines for the management of patients with metastatic colorectal cancer. Ann Oncol 2016;27:1386-422.

20. Austin PC. Optimal caliper widths for propensity-score matching when estimating differences in means and differences in proportions in observational studies. Pharm Stat 2011;10:150-61.

21. Mahnken AH. Current status of transarterial radioembolization. World J Radiol 2016;8:449-59.

22. Mosconi C, Gramenzi A, Ascanio S, et al. Yttrium-90 radioembolization for unresectable/recurrent intrahepatic cholangiocarcinoma: a survival, efficacy and safety study. Br J Cancer 2016;115:297-302. 


\section{Page 8 of 8}

23. Seidensticker R, Ricke J, Seidensticker M. Integration of chemoembolization and radioembolization into multimodal treatment of cholangiocarcinoma. Best Pract Res Clin Gastroenterol 2015;29:319-32.

24. Currie BM, Hoteit MA, Ben-Josef E, et al. Radioembolization-Induced Chronic Hepatotoxicity:

Cite this article as: Masthoff $M$, Schindler P, Harders F, Heindel W, Wilms C, Schmidt HH, Pascher A, Stegger L, Rahbar K, Wildgruber M, Köhler M. Repeated radioembolization in advanced liver cancer. Ann Transl Med 2020;8(17):1055. doi: 10.21037/atm-20-2658
Masthoff et al. Repeated radioembolization in advanced liver cancer

A Single-Center Cohort Analysis. J Vasc Interv Radiol 2019;30:1915-23.

25. Paprottka KJ, Schoeppe F, Ingrisch M, et al. Pretherapeutic factors for predicting survival after radioembolization: a single-center experience in 389 patients. Eur J Nucl Med Mol Imaging 2017;44:1185-93. 